\title{
Stress-induced extracellular Hsp72 is a functionally significant danger signal to the immune system
}

\author{
Jay Campisi, ${ }^{1,2}$ Ted H. Leem, ${ }^{2,3}$ and Monika Fleshner ${ }^{1,2}$ \\ 1Department of Integrative Physiology, University of Colorado, Boulder, CO 80309-0354, USA \\ ${ }^{2}$ Center for Neuroscience, University of Colorado, Boulder, CO 80309-0354, USA \\ ${ }^{3}$ University of Colorado Health Science Center, Department of Medicine, University of Colorado, Boulder, CO 80309-0354, USA
}

\begin{abstract}
Extracellular heat-shock proteins (eHsp) such as those belonging to the 70-kDa family of Hsp (eg, Hsp72) have been hypothesized to act as a "danger signal" to immune cells, promote immune responses, and improve host defense. The current study tested this hypothesis. Adult male F344 rats were exposed to an acute laboratory stressor (100, 5-second, 1.6-mA inescapable tail shocks) and challenged with Escherichia coli. The number of colony-forming units (CFU) of bacteria at the site of injection, the levels of eHsp72, the immune response to eHsp72 and E coliderived lipopolysaccharide (LPS), and the amount of time required to recover from in vivo bacterial challenge were measured. CFUs were reduced 2, 4, and 6 hours after injection of $E$ coli in rats exposed to stress. Rats exposed to stress had elevated eHsp72 that was elevated rapidly (25 minutes) and remained elevated in the circulation and at the inflammatory site (2 hours after stressor termination). Both stressor exposure and eHsp72 administration in the absence of stress resulted in a facilitated pattern of recovery after bacterial inflammation induced by subcutaneous $E$ coli injection. Rats exposed to acute restraint (100 minutes) did not demonstrate elevated circulating eHsp72 or a facilitated pattern of recovery after bacterial challenge. In vitro stimulation of rat splenocytes and macrophages with eHsp72 elevated nitric oxide (NO), tumor necrosis factor alpha (TNF- $\alpha$ ), interleukin (IL)-1beta, and IL-6, and this effect was specific to eHsp72 because it was not diminished by polymyxin B and was reduced by earlier heat-denature treatment. Stimulation of cells with eHsp72 combined with LPS resulted in a greater NO and cytokine response than that observed after stimulation with eHsp72 or LPS alone. In vivo, at the inflammatory site, the bacterial-induced NO response was potentiated by stress, and NO inhibition (L-NIO) reduced the stress-induced facilitation but had no effect on the control kinetics of bacterial inflammation recovery. Thus, these results lend support to the hypothesis that intense stressor exposure increases eHsp72, which acts as a danger signal to potentiate the NO response to bacterial challenge and facilitate recovery from bacterial inflammation.
\end{abstract}

\section{INTRODUCTION}

Heat-shock proteins (Hsp) are a family of highly conserved proteins that play a role in a number of physiological functions. The 70-kDa Hsp (Hsp70) family of proteins includes a constitutive 73-kDa protein (HSC73) and a highly stress-inducible 72-kDa protein (Hsp72) (Kiang and Tsokos 1998; Hartl 1996). During stress, a substantial increase in intracellular Hsp72 (iHsp72) synthesis occurs, and both the induction and the subsequent action of

Received 5 September 2002; Revised 25 March 2003; Accepted 27 March 2003.

Correspondence to: Monika Fleshner, Tel: 303 492-1483; Fax: 202 4926778; E-mail: fleshner@colorado.edu.
iHsp72 serve as protective functions for the cell (Kiang and Tsokos 1998; Hartl 1996). For example, the induction of Hsp72 gene transcription represses proinflammatory cytokine gene transcription by inhibiting nuclear factor$\kappa \mathrm{B}(\mathrm{NF}-\kappa \mathrm{B})$ activation (ie, HSF-1 stabilization of I-кB $\alpha$ ) (Cahill et al 1996, 1997; Housby et al 1999). The downregulation of proinflammatory cytokines protects the cell from a stressor that would otherwise result in injury or death (Yoo et al 2000). Furthermore, the high level of synthesized intracellular Hsp72 fortifies the cell, protecting it through Hsp72's role as a cellular chaperone (Lindquist and Craig 1988).

Although iHsp72 induction decreases cytokine production, extracellular Hsp (eHsp) can actually increase proin- 
flammatory cytokine production (Breloer et al 1999; Chen et al 1999; Multhoff et al 1999; Asea et al 2000). Recent evidence indicates that eHsp may be released from cells during conditions of cellular stress and may further promote local inflammation through activation of the innate immune system (Breloer et al 1999; Chen et al 1999; Multhoff et al 1999; Asea et al 2000). Investigations conducted by Chen et al (1999) and Kol et al (2000) indicate that human eHsp60 activates the innate immune system in a manner similar to lipopolysaccharide (LPS), resulting in the production of proinflammatory cytokines and nitric oxide (NO) in vitro. In addition, Panjwani et al (2002) found that eHsp70 stimulates inducible NO synthase (iNOS) and NO release from macrophages. Recent evidence suggests that eHsps exert their effects on innate immune cells through the MyD88/IRAK/NF-kappaB signal transduction pathway and that eHsp uses both TLR2 (receptor for gram-positive bacteria) and TLR4 (receptor for gram-negative bacteria) as well as the Toll/IL1 receptor signal pathway to transduce its proinflammatory signal (Asea et al 2000, 2002; Vabulas et al 2002).

Given that stressed or injured cells have elevated iHsp (Kiang and Tsokos 1998), necrotic cells release these proteins (Basu et al 2000), and eHsp activates the innate immune system (Kol et al 2000), others have suggested that Hsps could act as "danger signals" to the immune system (Colaco 1998; Moseley 1998; Chen et al 1999; Asea et al 2000; Ohashi et al 2000; Todryk et al 2000; Breloer et al 2001; Bethke et al 2002; Habich et al 2002; Vabulas et al 2002). The danger theory, first postulated by Matzinger (1994, 1998), proposes that immune activation involves danger and nondanger molecular recognition schemas. One important and unresolved issue for this theory is what molecules serve as danger signals to the immune system. There is recent evidence to support Hsps as reasonable candidates because they are released during times of immunological danger (ie, cellular stress and death) and they activate the immune system. Although Hsps fit the theoretical framework proposed by Matzinger, there is currently little or no in vivo experimental evidence to support this idea.

If the presence of a danger signal serves to facilitate or to target immune function, and eHsp72 acts as a danger signal, then an organism with an increased eHsp72 should have an improved immune response to some types of pathogenic challenge. For example, bacterial infections that are commonly resolved by inflammatory mediators might be especially sensitive to eHsp72 effects. Thus, the current studies examined the effect of exposure to an acute laboratory stressor on eHsp72 and inflammatory responses and tested the hypothesis that exposure to stress increases eHsp72, which then facilitates immune responses (eg, cytokines and NO) and improves host defense against bacterial infection.

\section{MATERIALS AND METHODS}

\section{Animals}

Adult male viral-free Fischer 344 (F344) rats (200-300 gms; Harlan Labs, San Diego, CA, USA) were caged individually in Plexiglas cages $(60 \times 30 \times 24 \mathrm{~cm})$ with food and water available ad libitum. The animal colonies were maintained in a pathogen-free barrier facility with a 12 : 12 hour light-dark cycle (lights were switched on from 0600 to 1800 hours). Rats were given at least 1 week to habituate to the colonies before experimentation. Body weights were monitored daily. All rats were handled and weighed each day for at least 2 days before each study began (4-12 rats per group per study). Care and use of the animals were in accordance with protocols approved by the University of Colorado Institutional Animal Care and Use Committee.

\section{Effect of stressor exposure on bacterial clearance at the inflammatory site}

If our hypothesis is correct, then an organism with an elevated eHsp72 should have an improved immune response to pathogenic challenge, especially one that involves proinflammatory responses. Because of recent evidence that eHsp may be released from cells during conditions of cellular stress (Breloer et al 1999; Chen et al 1999; Multhoff et al 1999; Asea et al 2000; Febbraio et al 2002) and that inescapable tail shock stress (details are given below) upregulates iHsp72 in a variety of tissues (Campisi et al 2002b), we postulated that stressor exposure would result in the release of eHsp72, perhaps from injured or dying cells, and facilitate innate immune responses. Thus, the initial study tested the hypothesis that stressor exposure would facilitate the killing or clearance of bacteria after inoculation with Escherichia coli (details are given below). We chose to challenge rats with bacteria subcutaneously because this challenge is known to stimulate an immediate innate, inflammatory response (Campisi et al 2002a) and macrophages and neutrophils are primarily responsible for host defense to this pathogen (Ali et al 1997). Furthermore, E coli was chosen because this type of bacteria is not normally present in subcutaneous tissue in nonchallenged animals. Thus, any E coli retrieved and cultured would be from the experimental challenge and not due to contamination with endogenous bacteria. One day before stressor exposure and E coli injection, an area on the rat's dorsal surface measuring approximately $5 \times 7 \mathrm{~cm}$ was shaved so that biopsy samples could be made easily. On the day of experimentation, rats were exposed to stress or were controls and were then immediately injected with E coli. At 2, 4, and 6 hours after bacterial challenge, representative rats were sacrificed, in- 
flammatory sites were removed, and bacteria were quantified (details are given below).

\section{Inescapable tail shock procedure}

Animals either remained undisturbed in their home cages as controls (no stress) or were exposed to inescapable tail shock (stress) (Fleshner et al 1998; Campisi et al 2002a). Stressed rats were transported to an adjacent room and placed in Plexiglas restraining tubes $(15 \times 7$ $\mathrm{cm})$. Contact beams were placed on the tail of the rat, and hundred 1.6-mA tail shocks (5-second duration, variable intertrial interval $\sim 60$ seconds; range 30-90 seconds) were administered. The total stress session lasted approximately 100 minutes. This acute laboratory stressor has been reported to increase NO (Fleshner et al 1998; Campisi et al 2002a) and proinflammatory cytokines (Johnson et al 2002) after antigen challenge as well as activate the autonomic nervous system (Fleshner 2000) and the hypothalamic-pituitary-adrenal axis (Fleshner et al 1993), and induce synthesis of iHsp72 in a variety of tissues (Campisi et al 2002b).

\section{Bacterial culture}

Escherichia coli (ATCC 15746) were purchased from American Type Culture Collection (Bethesda, MD, USA). Vial contents were rehydrated and grown overnight to maximal densities in $30 \mathrm{~mL}$ of brain-heart infusion (BHI; DIFCO Laboratories, Detroit, MI, USA) at $37^{\circ} \mathrm{C}, 95 \%$ air + $5 \% \mathrm{CO}_{2}$. Cultures were then aliquoted into $1 \mathrm{~mL}$ of $\mathrm{BHI}$ supplemented with $10 \%$ glycerol and frozen at $-70^{\circ} \mathrm{C}$. These vials constituted the stock cultures. All experiments used bacteria from these stock cultures.

One day before experimentation, stock cultures were thawed and cultured overnight ( $\sim 19$ hours) in $35 \mathrm{~mL}$ of $\mathrm{BHI}\left(37^{\circ} \mathrm{C}, 95 \%\right.$ air $\left.+5 \% \mathrm{CO}_{2}\right)$. The number of bacteria in cultures was quantified by extrapolating from previously determined growth curves (Deak et al 1999; Campisi et al 2002a). Cultures were then centrifuged for 15 minutes at $3000 \mathrm{rpm}$ and the supernatants discarded, and bacteria were resuspended in sterile phosphate-buffered saline (PBS).

\section{Bacterial quantification at the inflammatory site}

Viable bacteria were quantified according to the protocol of Rojas et al (2002), with slight modifications. Briefly, inflammatory sites were removed using a 4-mm punch biopsy sample and homogenized in $1 \mathrm{~mL}$ of PBS. Two inflammatory sites were collected for each rat from the inflammatory site and combined. An additional control site was collected for each rat from an area of skin distal to the injection site. Homogenates were then serially di- luted (1:100), plated on MacConkey II agar (Fisher, Pittsburgh, PA, USA), and incubated for 15 hours. MacConkey II agar is a selective and differential medium that inhibits the growth of gram-positive bacteria and is selective for aerobic gram-negative bacilli. This medium promotes detection of coliform organisms and enteric pathogens such as $E$ coli and adds to our confidence that measures of $E$ coli are not contaminated with other endogenous bacteria. Quantification of the bacterial colonies was performed by an independent observer blind to the experimental condition of the rat.

\section{Effect of stressor exposure on circulating and tissue eHsp72}

According to our hypothesis, stressor exposure should trigger the release of a danger signal (ie, eHsp72). To test the effect of stress (inescapable tail shocks) on circulating eHsp72, blood samples (details are given below) were taken the day before the experimental procedure (baseline), after 25 tail shocks (25 minutes), after 100 tail shocks (100 minutes), and 2 hours after stressor termination. Time-matched blood samples were taken from nonstressed home cage control (no stress) animals. To test the effect of stressor exposure on tissue eHsp72, rats were exposed to either inescapable tail shock stress or no stress and, immediately after stressor termination, were injected either with $E$ coli or with sterile saline. Two hours after the $E$ coli challenge and stress or control treatment, rats were anesthetized with $0.8 \mathrm{~mL}$ of sodium pentobarbital and sacrificed by cervical dislocation. Inflammatory sites were harvested as described previously (Campisi et al 2002a), and eHsp72 was measured after 1 hour in culture medium.

\section{Blood sampling and eHsp72 measurement}

The rat was removed from its home cage, gently wrapped in a towel, and lightly restrained with a Velcro strap. The tail was exposed, and a small nick was made in a lateral tail vein with a scalpel (no. 15 blade), and the tail was gently stroked until a volume of approximately 200-300 $\mu \mathrm{L}$ of whole blood was obtained in ethylenediaminetetraacetic acid (Sigma, St. Louis, MO, USA)-treated microfuge tubes. Samples collected from rats during stress required that the rats remain in the stress restraint tubes and the contact beams be temporarily removed while the tail nick was performed. The entire sampling procedure was accomplished within 2 minutes of approaching the cage or restraint tube. Samples were spun immediately in a refrigerated centrifuge, and plasma was aliquoted and stored at $-20^{\circ} \mathrm{C}$ until the time of assay. Hsp72 was measured from plasma or culture supernatants using commercially available enzyme-linked immunosorbent assays 
(ELISAs) for rat eHsp72 (Stressgen Biotechnologies, Victoria, British Columbia, Canada). Briefly, a mouse monoclonal antibody specific for inducible Hsp70 (ie, Hsp72) was precoated on the wells of the Hsp72 immunoassay plate. Inducible Hsp70 (ie, Hsp72) was captured by the immobilized antibody was detected with an Hsp72-specific, biotinylated rabbit polyclonal antibody. The biotinylated antibody was subsequently bound by an avidinhorseradish peroxidase conjugate. The assay was developed with tetramethyl-benzidine substrate and stopped with acid stop solution, which converted the endpoint color to yellow. The intensity of the color was then measured at $450 \mathrm{~nm}$ using a microplate reader. The assay is specific for native and recombinant inducible Hsp70 (ie, Hsp72), and it does not detect other Hsp70 family members such as constituitive HSC70, Grp78, DnaK, Hsp71, or Hsp60 (Stressgen Biotechnologies). Both the intra-assay and the interassay coefficient of variation is $<10 \%$. Validation of Hsp72 changes in rodents using a quantitative ELISA has been verified using Western blot analyses and reported to be more sensitive and more quantifiable than the Western blot technique (Milne and Noble 2002). Samples were assayed at optimal concentrations and according to manufacturer's instructions.

\section{Effect of stressor exposure on inflammation}

If stress elevates eHsp72, and eHsp72 facilitates bacterial clearance, then rats exposed to stress should demonstrate a facilitated pattern of recovery after bacterial challenge. Therefore, the purpose of this experiment was to determine the effect of inescapable tail shock stress on recovery from bacterial induced inflammation. One day before stressor exposure and $E$ coli injection, an area on the rat's dorsal surface measuring approximately $5 \times 7 \mathrm{~cm}$ was shaved so that inflammation could easily be quantified. On the day of experimentation, injections were given subcutaneously in the center of the back. Previous work in our laboratory determined that an $E$ coli dose of $\sim 2.5 \times$ $10^{9}$ colony-forming units (CFU) produces a reliable inflammatory response (Campisi et al 2002a). Therefore, unless noted otherwise, rats were injected with $\sim 2.5 \times$ $10^{9} \mathrm{CFU} / 250 \mu \mathrm{L}$. The diameter of inflammation was measured repeatedly across time using a digital caliper (to the nearest tenth of a millimeter) by the same researcher who was blind to the experimental group of the rat. Care was taken to ensure that all measurements were made on the same region of the dorsum. Control rats were injected with $E$ coli but not exposed to stress.

\section{Effect of restraint on circulating eHsp72 and inflammation}

To determine whether tail shock is necessary to elevate circulating eHsp72 and facilitate bacterial recovery, or whether restraint or manipulation of the animals would be sufficient, 2 control studies were conducted. To test the effect of restraint (details below) on circulating eHsp72, blood samples were taken as above after 25 minutes of restraint or after 100 minutes of restraint. Time-matched blood samples were taken from nonstressed home cage control animals. If restraint elevates eHsp72, and eHsp72 facilitates bacterial clearance, then rats exposed to restraint should demonstrate a facilitated pattern of recovery after bacterial challenge. Therefore, the purpose of the second control experiment was to determine the effect of restraint on recovery from bacterial-induced inflammation. Rats were exposed to restraint or remained in their home cages. Immediately after the termination of 100 minutes of restraint, all rats were injected subcutaneously with $\sim 2.5 \times 10^{9} \mathrm{CFU}$ of $E$ coli, and inflammation diameter was measured daily.

\section{Restraint procedure}

The restraint procedure is identical to that used for inescapable shock stress, except that no tail shocks were delivered. Specifically, rats were transported to an adjacent room and placed in Plexiglas restraining tubes (15 $\times 7 \mathrm{~cm}$ ). The total restraint session lasted 100 minutes.

\section{Effect of in vivo eHsp72 on bacterial inflammation}

This study tested the effect of in vivo eHsp72 on bacterial inflammation. If eHsp72 is contributing to facilitated functional recovery, eHsp72 in the absence of stressor exposure should also facilitate recovery from bacterial challenge. Rats were injected subcutaneously with 0,10 , or 20 $\mu \mathrm{g}$ of Hsp72 (SPP-758; Stressgen Biotechnologies) and E coli in Freund incomplete adjuvant (Sigma; $250-\mu \mathrm{L}$ total volume $)$ at a dose $\left(\sim 2.5 \times 10^{8} \mathrm{CFU}\right)$ that produces a similar inflammatory response to that observed without adjuvant. Freund incomplete adjuvant was used to ensure that the injected eHsp72 would stay at the inflammatory site. Inflammation diameters were recorded daily.

\section{Effect of in vitro eHsp72 stimulation of NO and cytokines from rat cells}

If increases in eHsp72 facilitate host defense against $E$ coli challenge, then eHsp72 both with and without LPS should increase bactericidal products such as NO and proinflammatory cytokines. Although it has been previously reported that eHsp72 stimulates $\mathrm{NO}$ and proinflammatory cytokines from human and murine cells, the effect of eHsp72 has not been tested in rat cells previously. Thus, the following studies examined F344 rat splenic and peritoneal cell production of $\mathrm{NO}$ and cytokines after in vitro stimulation with eHsp72, LPS (a com- 
ponent of gram-negative bacteria), and eHsp72 + LPS. Spleen and peritoneal cavity cells were cultured in the presence of $10 \mu \mathrm{g} / \mathrm{mL}$ of Hsp72 protein (SPP-758; Stressgen Biotechnologies), $50 \mu \mathrm{g} / \mathrm{mL}$ of $E$ coli-derived LPS (E. coli, 0111:B4; Sigma), $10 \mu \mathrm{g} / \mathrm{mL}$ of Hsp72 protein combined with $50 \mu \mathrm{g} / \mathrm{mL}$ of LPS, or an equal volume of culture media. Immediately after incubation for 24 hours, nitrite was measured, and the remaining culture supernatant was collected and stored at $-20^{\circ} \mathrm{C}$ until the time of cytokine assay. Preliminary studies indicated that 24 hours in culture was the optimal time to measure nitrite and cytokines (data not shown). Cytokines were measured from plasma or culture supernatants using commercially available ELISAs for tumor necrosis factor (TNF)- $\alpha$, interleukin (IL)-1 $\beta$ (R and D Systems, Minneapolis, MN, USA), and IL-6 (BioSource, Camarillo, CA, USA). Samples were assayed at optimal concentrations and according to the manufacturer's instructions.

A series of control studies tested the dose responsiveness and specificity of the effects of eHsp72, which is necessary to establish that effects of eHsp72 are specific to that protein and are not due to endotoxin contamination. This was accomplished in a number of ways. First, a dose-response function of nitrite production after eHsp72 stimulation was generated. Spleen cells were cultured in the presence of $0.3-28.9 \mu \mathrm{g} / \mathrm{mL}$ of Hsp72 (SPP758; Stressgen Biotechnologies) or a vehicle (details are given below). After incubation for 24 hours, culture supernatant nitrite was measured in the culture supernatants through the colorimetric Griess reaction as described previously (Fleshner et al 1998). Second, the endotoxin level of the recombinant Hsp72 used in these studies was measured by Limulus amebocyte lysate assay (BioWhittaker, Walkersville, MD, USA). Third, polymyxin B (PMB, Sigma) an inhibitor of LPS (Duff and Atkins 1982; Golenbock et al 1991), was added to cell culture samples (10-200 $\mu \mathrm{g} / \mathrm{mL}$, only $100-\mu \mathrm{g} / \mathrm{mL}$ data shown) immediately before the addition of stimulant $(50 \mu \mathrm{g} / \mathrm{mL}$ of LPS or $10 \mu \mathrm{g} / \mathrm{mL}$ of Hsp72 protein). Finally, Hsp72 was heat treated at $100^{\circ} \mathrm{C}$ for 90 minutes before stimulation of cells. This treatment has been reported previously to heat denature Hsp72 but not LPS (Kol et al 2000).

\section{Details of cell isolation and culture}

All cell culture studies were conducted on rats not exposed earlier to stressor or manipulated in any way. Peritoneal cavity cells were removed by lavage. Cold dissection medium ( $30 \mathrm{~mL}$ of Iscove medium [GIBCO BRL Life Technologies, Frederick, MD, USA] with $1 \%$ penicillinstreptomycin [GIBCO]) was placed into the peritoneal cavity, the abdomen briefly massaged, and the fluid removed $(20 \mathrm{~mL})$. The medium was centrifuged, and the cells were resuspended to $1.0 \times 10^{6}$ cells $/ \mathrm{mL}$ in culture medium (Iscove medium [GIBCO] containing 10\% fetal bovine serum [GIBCO] with $1 \%$ penicillin-streptomycin [GIBCO] and $1 \%$ L-glutamine [GIBCO]). Cells were counted using a Coulter particle counter. Spleens were aseptically dissected from each rat and then placed individually in dissection medium over ice. Spleens were dissociated using sterile, modified, glass tissue homogenizers. Spleen cells were resuspended in culture medium at $5 \times 10^{6}$ cells $/ \mathrm{mL}$ and placed into sterile 24-well flatbottom culture plates (Falcon, Becton Dickinson Labware, Franklin Lakes, NJ, USA). Cells (300 $\mu \mathrm{L} /$ well) were incubated at $37^{\circ} \mathrm{C}$ in $95 \%$ air $+5 \% \mathrm{CO}_{2}$.

\section{Effect of stressor exposure and $E$ coli on inflammatory site NO production}

If stress elevates eHsp72, and eHsp72 stimulates immune cells to produce inflammatory mediators, then stress should result in elevated inflammatory products in vivo. Thus, this study examined the effect of inescapable tail shock stress on NO responses at the inflammatory site. Rats were exposed to stress or remained in their home cages as controls and were injected with $E$ coli or saline. Two hours after stressor termination, rats were sacrificed, and inflammatory sites were aseptically dissected, cut into smaller equal sections, put into $2 \mathrm{~mL}$ of Hanks media (GIBCO), and placed in culture (Campisi et al 2002a). Nitrite was measured from the supernatants after 1, 2, 3, or 4 hours in culture.

\section{Effect of NO inhibition on stress-induced changes in inflammation}

The following studies tested the hypothesis that stressinduced potentiation of $\mathrm{NO}$ at the inflammatory site contributes to stress-induced facilitation of recovery from bacterial inflammation. L-N $N^{5}$-(1-Iminoethyl)-ornithine dihydrochloride (L-NIO; Cayman Chemical, Ann Arbor, MI, USA) is a competitive, irreversible inhibitor of all NOS isoforms (McCall et al 1991). The first study tested the effectiveness of L-NIO in inhibiting bacterial-induced NO elevation in vivo. L-NIO was resuspended in sterile PBS to a concentration of $5.0 \mathrm{mg} / \mathrm{mL}$, a dose reported to effectively reduce NO (Rodenas et al 1998), on the day of the experiment. All rats were injected with $E$ coli. After 1 hour, rats were injected again with either the L-NIO or the PBS vehicle $(300 \mu \mathrm{L})$ into the inflammatory site. Rats were sacrificed 1 hour after L-NIO injection, and their inflammatory site was aseptically dissected and placed in culture (Campisi et al 2002a). Supernatants were collected, and nitrite was measured after 1, 18, 24, and 48 hours in culture.

The second study tested the effect of L-NIO on stressinduced changes in inflammation resolution. Rats were 


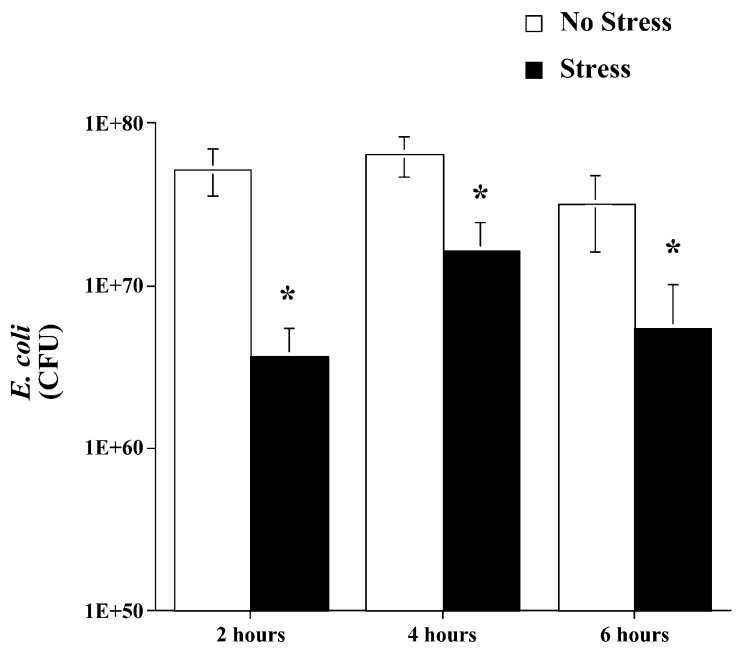

Time afer $E$. coli challenge

Fig 1. Adult male F344 rats ( $n=7 /$ group/time point) either were exposed to 100, 5-second, 1.6-mA inescapable tail shocks (stress) or remained in their home cages (no stress). Immediately after stressor termination, all rats were injected subcutaneously with live $E$ coli $\left(\sim 2.5 \times 10^{9}\right.$ colony-forming units [CFU]). Rats were sacrificed 2,4 , or 6 hours after bacterial challenge, and inflammatory sites, previously inoculated with $E$ coli, were excised. Two sites were collected for each rat and combined. Inflammatory sites were homogenized, plated, and quantified. No viable bacteria were recovered from control skin sites. The bacterial counts (CFU) are presented in scientific nomenclature on a $\log _{10}$ scale. All figures represent mean \pm standard error of the mean. Stress vs no stress, F-PLSD ${ }^{*} P<$ 0.05 .

either exposed to inescapable tail shock or remained in their home cages as controls. Immediately after the termination of stress, all rats were injected with $E$ coli. Rats were then injected with equal volumes of either L-NIO or vehicle at $0,30,60,90,120,150$, and 180 minutes after the $E$ coli injection. Inflammation measurements were taken daily.

\section{Data analysis}

Studies involving multiple time measures used repeated measure analysis of variance (RMANOVA), whereas all other studies used ANOVA to determine whether main effects were present. If significant time by main effect interactions (RMANOVA) or main effects (ANOVA) were present, Fisher-protected least significant difference (F-PLSD) post hoc analyses were conducted. Alpha was set at 0.05 . All figures are shown with group means \pm standard error of the mean.

\section{RESULTS}

\section{Effect of stressor exposure on bacterial clearance at the inflammatory site}

As shown in Figure 1, inescapable tail shock stress resulted in a significant decrease in viable bacteria (ie, CFU) at the inflammatory site. A significant main effect of group (stress vs no stress) indicated that stress resulted in a decrease in inflammatory site $E$ coli $(F(1,32)=15.693$, $P=0.0004)$. Post hoc analyses revealed that the number of CFU of E coli was decreased 2, 4, and 6 hours after bacterial challenge in rats exposed to stress compared with controls. No viable bacteria were detectable in control tissues. Thus, all $E$ coli CFU measured were from the experimental challenge and were not contaminated with endogenous $E$ coli.

\section{Effect of stressor exposure on circulating and tissue eHsp72}

As shown in Figure 2A, inescapable tail shock stress resulted in a significant increase in circulating eHsp72. A significant main effect of group (stress vs no stress) indicated that stress resulted in an increase in eHsp72 $(F(1,10)=11.831, P=0.01)$. Post hoc analyses revealed that levels of eHsp72 increased rapidly after the onset of stress ( 25 minutes or after 25 shocks) and remained elevated for at least 2 hours after stressor termination.

Figure 2B depicts the effect of stress on tissue eHsp72. Stress-induced eHsp72 was elevated at the inflammatory site only when rats were exposed to bacterial challenge (Fig 2B). Statistical analysis indicated a significant stress by bacteria interaction $(F(1,10)=6.335, P=0.03)$.

\section{Effect of stressor exposure on inflammation}

The effect of inescapable tail shock stress on inflammation diameter is shown in Figure 3. Stress had a significant effect on inflammation diameter across the 14 days (group by time interaction) $(F(14,84)=41.089, P \leq$ $0.0001)$. Rats that were injected with $E$ coli immediately after stressor exposure had a $38 \%$ reduction (22.2 vs 36.8 $\mathrm{mm} ; P \leq 0.0001)$ in inflammation, as measured by diameter on day 1 , and demonstrated a facilitated pattern of recovery throughout the study compared with control animals. Post hoc analysis indicated that rats exposed to stress had significantly reduced inflammation diameter measures on each day of the study $(P<0.05$, days $1-14)$.

\section{Effect of restraint on circulating eHsp72 and inflammation}

As shown in Figure 4A, restraint did not result in a significant increase in circulating eHsp72 at any time point examined $(P>0.05)$. The effect of restraint on inflammation diameter is shown in Figure 4B. In contrast to inescapable tail shock stress, restraint alone did not have a significant effect on inflammation diameter $(P>0.05)$. Rats that were injected with $E$ coli immediately after restraint had a similar maximum inflammation diameter 

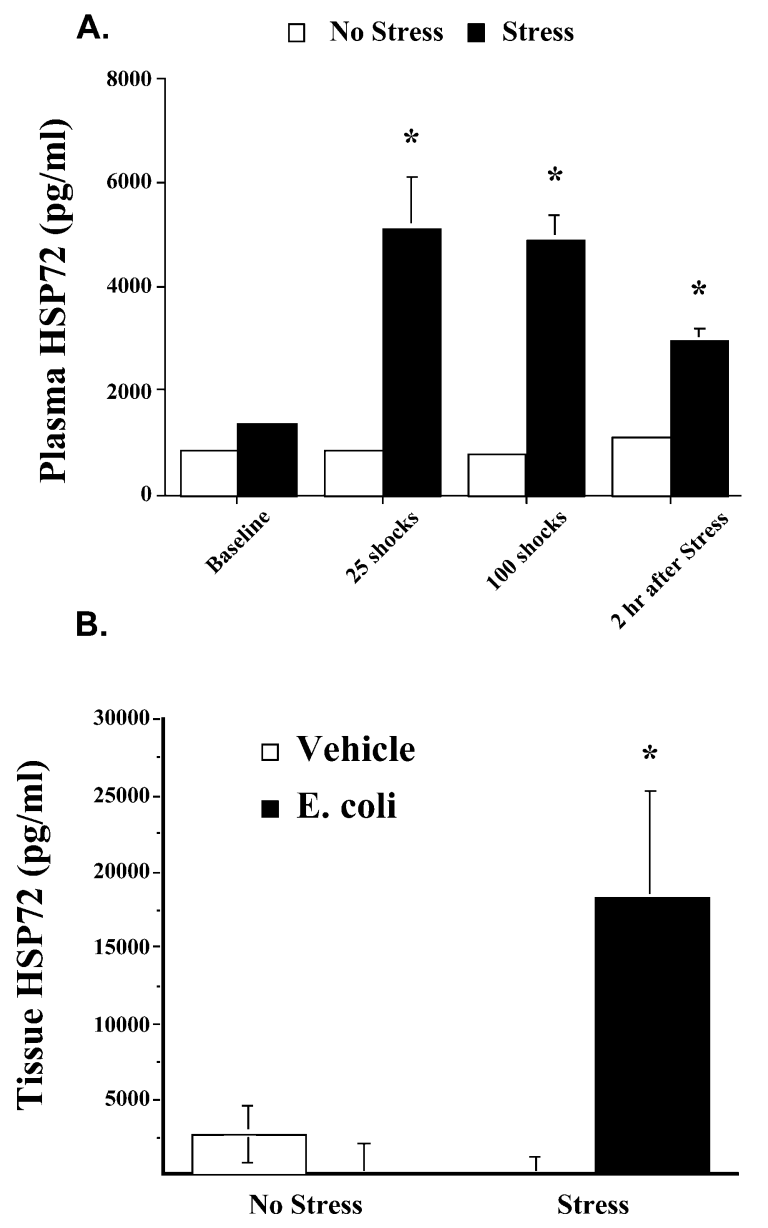

\section{Inflammatory site HSP72}

Fig 2. (A) Adult male F344 rats ( $n=4 /$ group) either were exposed to 100,5 -second, 1.6-mA inescapable tail shocks (stress) or remained in their home cages (no stress). Blood samples were taken the day before the experimental procedure (baseline), after 25 tail shocks (25 minutes), after 100 tail shocks (100 minutes), and 2 hours after stressor termination. Time-matched blood samples were taken from nonstressed home cage controls animals, and eHsp72 was measured. (B) Rats $(n=16)$ either were exposed to inescapable tail shocks (stress) or remained in their home cages (no stress). Immediately after stressor termination, rats ( $n=4$ /group) were injected either with $E$ coli or with saline (vehicle). Two hours after $E$ coli challenge and stress or no-stress treatment, rats were sacrificed, inflammatory tissue was harvested and placed in culture, and eHsp72 was measured. All figures represent mean \pm standard error of the mean. (A) Stress vs no stress, F-PLSD ${ }^{*} P<0.05$. (B) Stress (E coli) vs stress (vehicle), F-PLSD ${ }^{*} P<0.05$.

(restraint $=33.98 \mathrm{~mm}$ vs no stress $=30.88 \mathrm{~mm}$ ) on day 1 and demonstrated the same pattern of recovery throughout the study compared with animals not exposed to restraint.

\section{Effect of in vivo eHsp72 on bacterial inflammation}

Figure 5 shows the effect of administration of Hsp72 on bacterial inflammation resolution in the absence of stress.

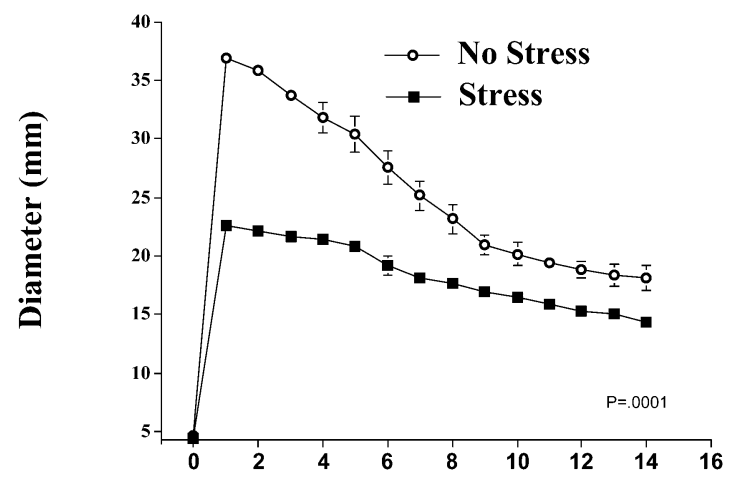

Day after subcutaneous $E$. coli challenge

Fig 3. Adult male F344 rats ( $n=4 /$ group) either were exposed to 100,5 -second, 1.6-mA inescapable tail shocks (stress) or remained in their home cages (no stress). Immediately after stressor termination, all rats were injected subcutaneously with live $E$ coli $(\sim 2.5$ $\times 10^{9}$ colony-forming units). Inflammation was measured daily. Group (stress vs no stress) by time interaction, $P=0.0001$.

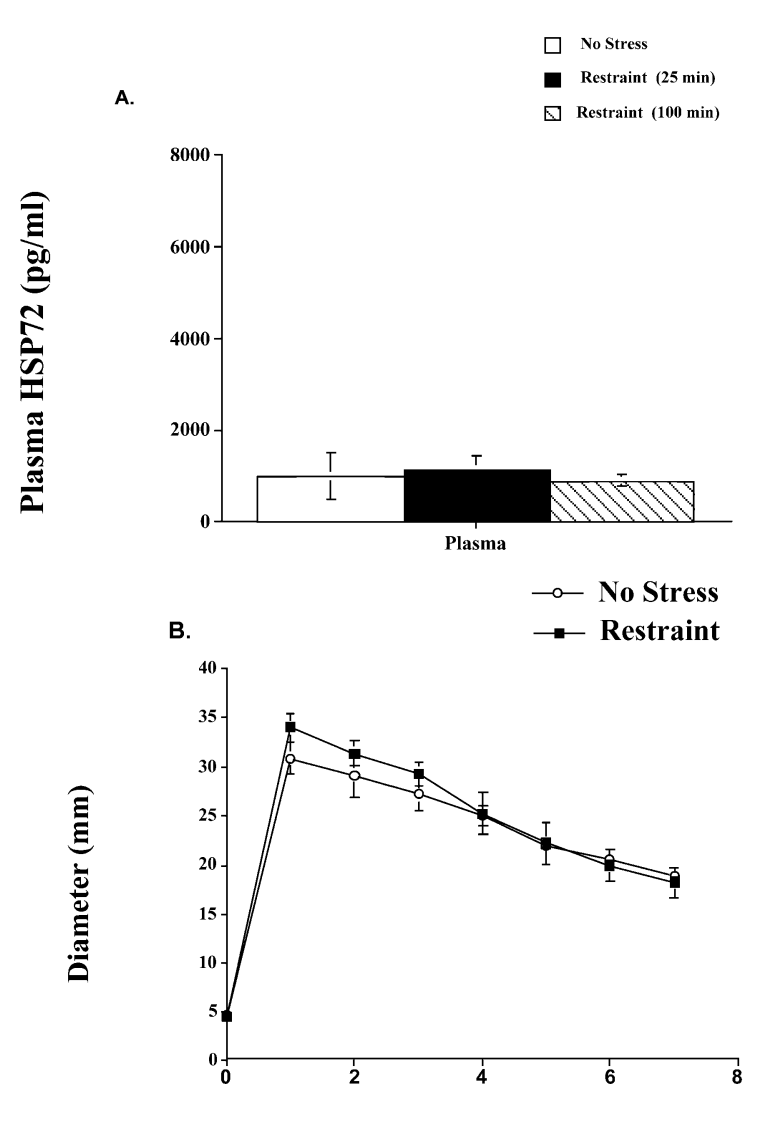

Day after subcutaneous $E$. coli challenge

Fig 4. (A) Adult male F344 rats ( $n=5 /$ group) either were exposed to an acute restraint procedure (restraint) or remained in their home cages (no stress). Blood samples were taken after 25 and 100 minutes of restraint. Time-matched blood samples were taken from nonstressed home cage controls (no stress) animals, and eHsp72 was measured. (B) Rats ( $n=5 /$ group) either were exposed to 100 minutes of restraint (restraint) or remained in their home cages (no stress). Immediately after restraint, all rats were injected subcutaneously with live $E$ coli ( $\sim 2.5 \times 10^{9}$ colony-forming units). Inflammation was measured daily. 


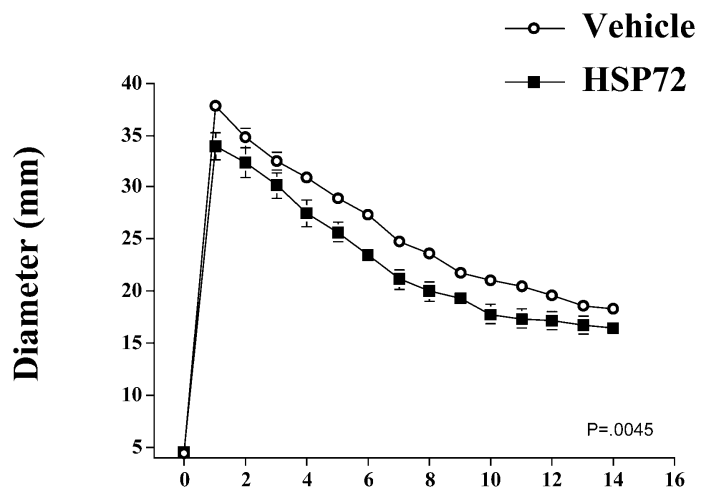

Day after subcutaneous E.coli challenge

Fig 5. Adult male F344 rats ( $n=5$ or 6/group) were subcutaneously injected with either $0 \mu \mathrm{g}$ or $20 \mu \mathrm{g}$ of Hsp72 and E coli $(\sim 2.5$ $\times 10^{8}$ colony-forming units) in Freund incomplete adjuvant. Inflammation diameters were recorded daily. Group (vehicle vs Hsp72) by time interaction, $P=0.0045$.

Hsp72 injection significantly altered inflammation diameter. Rats injected with $20 \mu \mathrm{g}$ of Hsp72 and E coli had a $10 \%$ reduction ( 33.95 vs $37.838 \mathrm{~mm} ; P=0.0127)$ in inflammation compared with vehicle $E$ coli-injected rats measured by diameter on day 1 , which persisted across time. Statistical analysis revealed a significant group $\times$ time interaction $(F(2,224)=7.703, P=0.0045)$ on inflammation diameter. Post hoc examination indicated that these differences in diameter persisted for days 1-12 after bacterial challenge. In contrast, rats injected with $10 \mu \mathrm{g}$ of Hsp72 had no change in inflammation (data not shown).

\section{Effect of in vitro Hsp72 stimulation of NO and cytokines}

Both F344 rat cell populations released nitrite and cytokines in response to Hsp72. As shown in Figure 6, splenic nitrite (Fig 6A), TNF- $\alpha$ (Fig 6B), IL-1 $\beta$ (Fig 6C), and IL-6 (Fig 6D) were all elevated after Hsp72 and LPS stimulation. ANOVA indicated a main effect of treatment (vehicle vs Hsp72 vs LPS vs Hsp72 + LPS) on spleen nitrite $(F(3,20)=9.832, P=0.0003), \mathrm{TNF}-\alpha(F(3,20)=10.815, P$ $=0.0002), \operatorname{IL}-1 \beta(F(3,20)=30.923, P \leq 0.0001)$, and IL-6

Fig 6. Adult male F344 rats $(n=12)$ were sacrificed, and spleens were aseptically harvested. Spleen cells $\left(5 \times 10^{6}\right.$ cells $/ \mathrm{mL}, 300 \mu \mathrm{L} /$ well) were cultured in the presence of $10 \mu \mathrm{g} / \mathrm{mL}$ of Hsp72 protein, $50 \mu \mathrm{g} / \mathrm{mL}$ of lipopolysaccharide (LPS), $10 \mu \mathrm{g} / \mathrm{mL}$ of Hsp72 protein combined with $50 \mu \mathrm{g} / \mathrm{mL}$ of LPS, or an equal volume of culture media. After incubation for 24 hours, (A) nitrite, (B) tumor necrosis factor- $\alpha,(C)$ interleukin (IL)-1 $\beta$, and (D) IL-6 were measured in the culture supernatants. All figures represent mean \pm standard error of the mean. (A-D) Stimulation (Hsp72, LPS, Hsp72 + LPS) vs media, F-PLSD ${ }^{*} P<0.05$; Hsp72 + LPS vs Hsp72 or LPS alone, F-PLSD $\# P<0.05$.
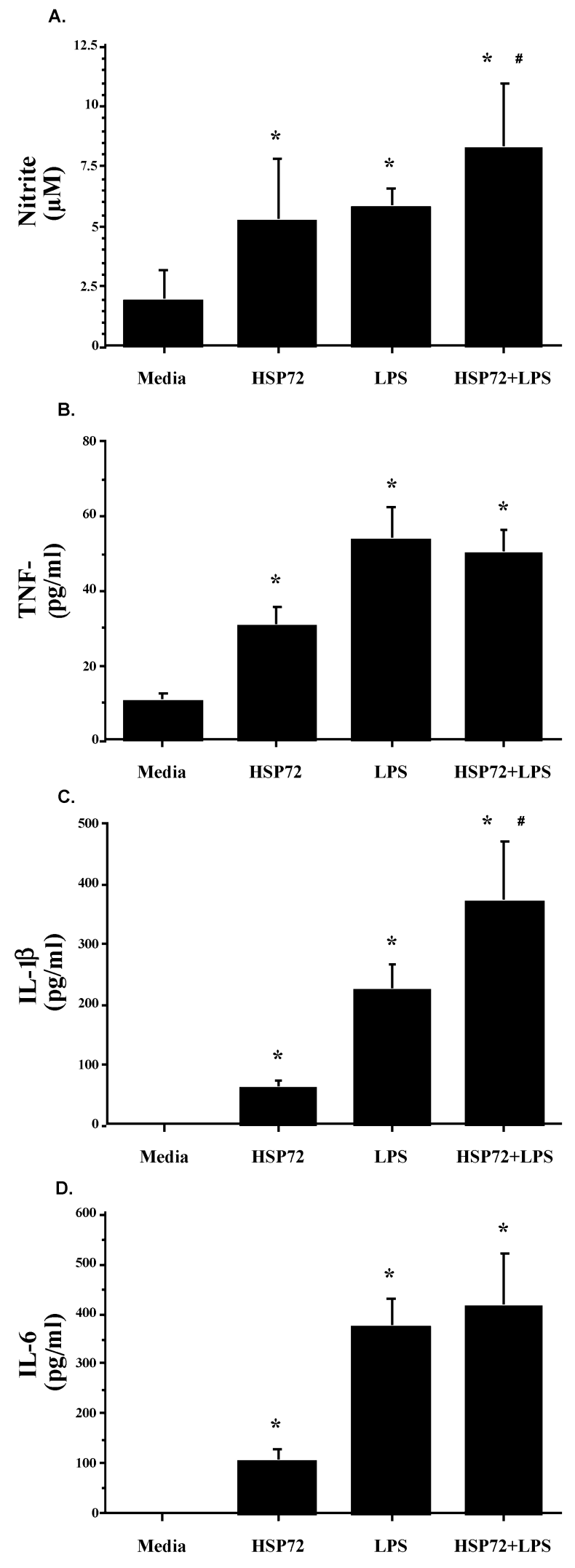
A.
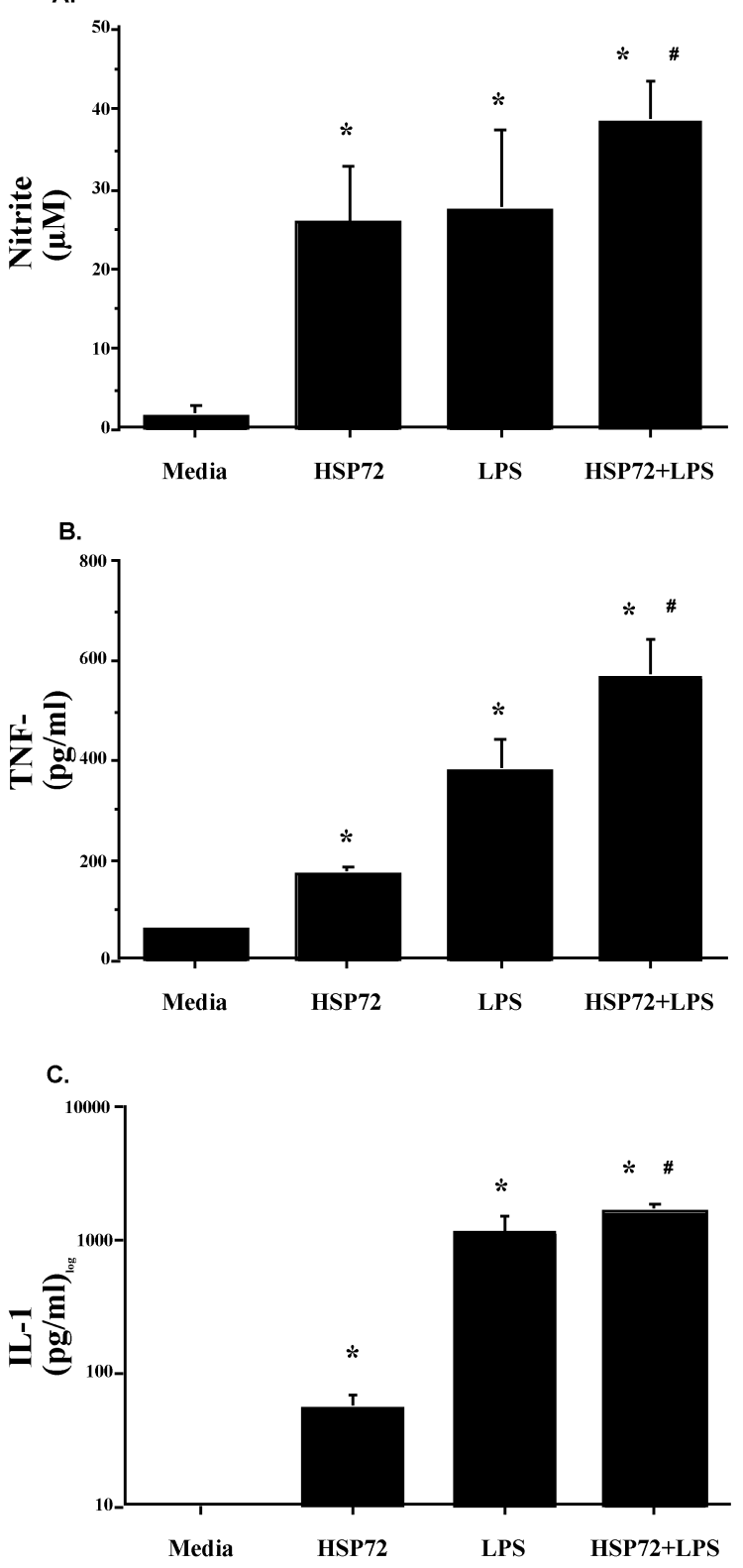

D.

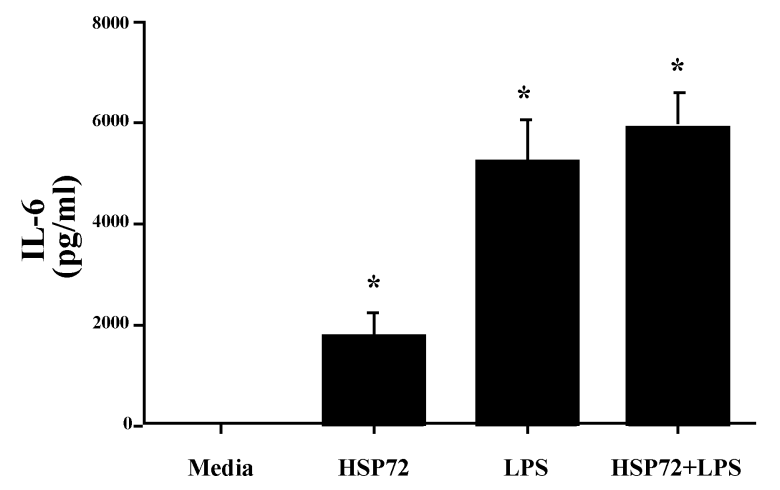

Fig 7. Adult male F344 rats $(n=12)$ were sacrificed, and peritoneal cells were aseptically harvested. Peritoneal cavity cells $(1 \times$ $10^{6}$ cells $/ \mathrm{mL}, 300 \mu \mathrm{L} /$ well) were cultured in the presence of $10 \mu \mathrm{g} /$ $\mathrm{mL}$ of Hsp72 protein, $50 \mu \mathrm{g} / \mathrm{mL}$ of lipopolysaccharide (LPS), $10 \mu \mathrm{g} /$

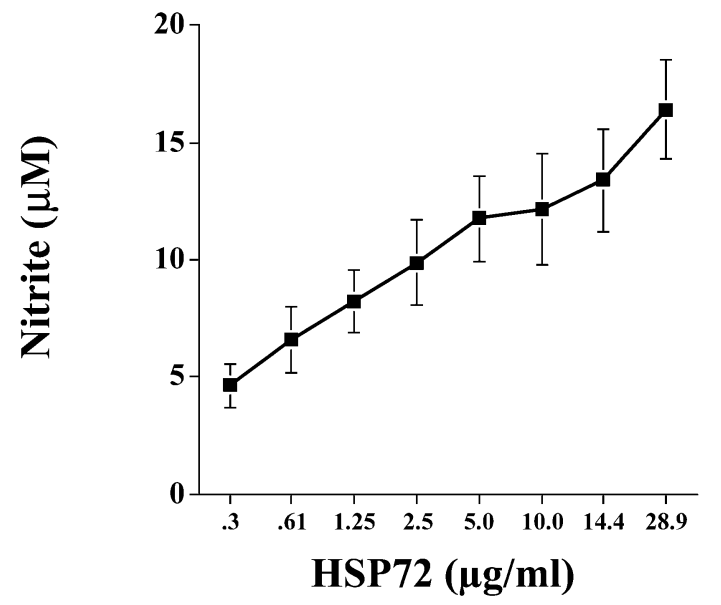

Fig 8. Adult male F344 rats $(n=6)$ were sacrificed, and spleens were aseptically harvested. Spleen cells $\left(5 \times 10^{6} \mathrm{cells} / \mathrm{mL}, 300 \mu \mathrm{L} /\right.$ well) were cultured in the presence of $0.3-28.9 \mu \mathrm{g} / \mathrm{mL}$ of Hsp72 or vehicle. After incubation for 24 hours, culture supernatant nitrite was measured. All figures represent mean \pm standard error of the mean.

$(F(3,20)=13.173, P \leq 0.0001)$. The same pattern of cytokine response was also reported for peritoneal cell nitrite (Fig 7A; $F(3,20)=31.782, P \leq 0.0001)$, TNF- $\alpha$ (Fig $7 \mathrm{~B} ; F(3,20)=33.785, P \leq 0.0001)$, IL-1 $\beta$ (Fig $7 \mathrm{C} ; F(3,20)$ $=39.586, P \leq 0.0001)$, and IL-6 $($ Fig $7 D ; F(3,20)=32.542$, $P \leq 0.0001)$. Post hoc analysis indicated that both Hsp72 and LPS produced significantly greater cytokines than media in both cell populations for every cytokine. Analysis also indicated that spleen cells stimulated with Hsp72 + LPS responded with a greater nitrite $(P=0.05)$ and IL-1 $\beta(P=0.002)$ response than that observed after stimulation with Hsp72 or LPS alone. Peritoneal cells stimulated with Hsp72 + LPS also released more nitrite $(P=0.009)$, TNF- $\alpha(P=0.002)$, and IL-1 $\beta(P=0.01)$ than that observed with either stimulating agent alone.

The control studies demonstrated that the effect was dose responsive, specific to eHsp72, and not due to endotoxin contamination of the protein. As shown in Figure 8, F344 rat spleen cells responded to stimulation with Hsp72 in culture by producing nitrite in a dose-dependent manner. Analysis revealed a significant main effect of treatment (media vs Hsp72) $(F(11,60)=6.822, P \leq$ 0.0001 ), and post hoc tests indicated that a dose as low as $1.25 \mu \mathrm{g}$ or $0.375 \mu \mathrm{g} /$ well was sufficient to produce nitrite amounts significantly greater than media $(P=$ 0.01). The possibility that LPS contamination of Hsp72

$\mathrm{mL}$ of Hsp72 protein combined with $50 \mu \mathrm{g} / \mathrm{mL}$ of LPS, or an equal volume of culture media. After incubation for 24 hours, (A) nitrite, (B) tumor necrosis factor- $\alpha$, (C) interleukin (IL)- $1 \beta$, and (D) IL-6 were measured in the culture supernatants. All figures represent mean \pm standard error of the mean. (A-D) Stimulation (Hsp72, LPS, Hsp72 + LPS) vs media, F-PLSD ${ }^{*} P<0.05$; Hsp72 + LPS vs Hsp72 or LPS alone, F-PLSD \#P $<0.05$. 
A.
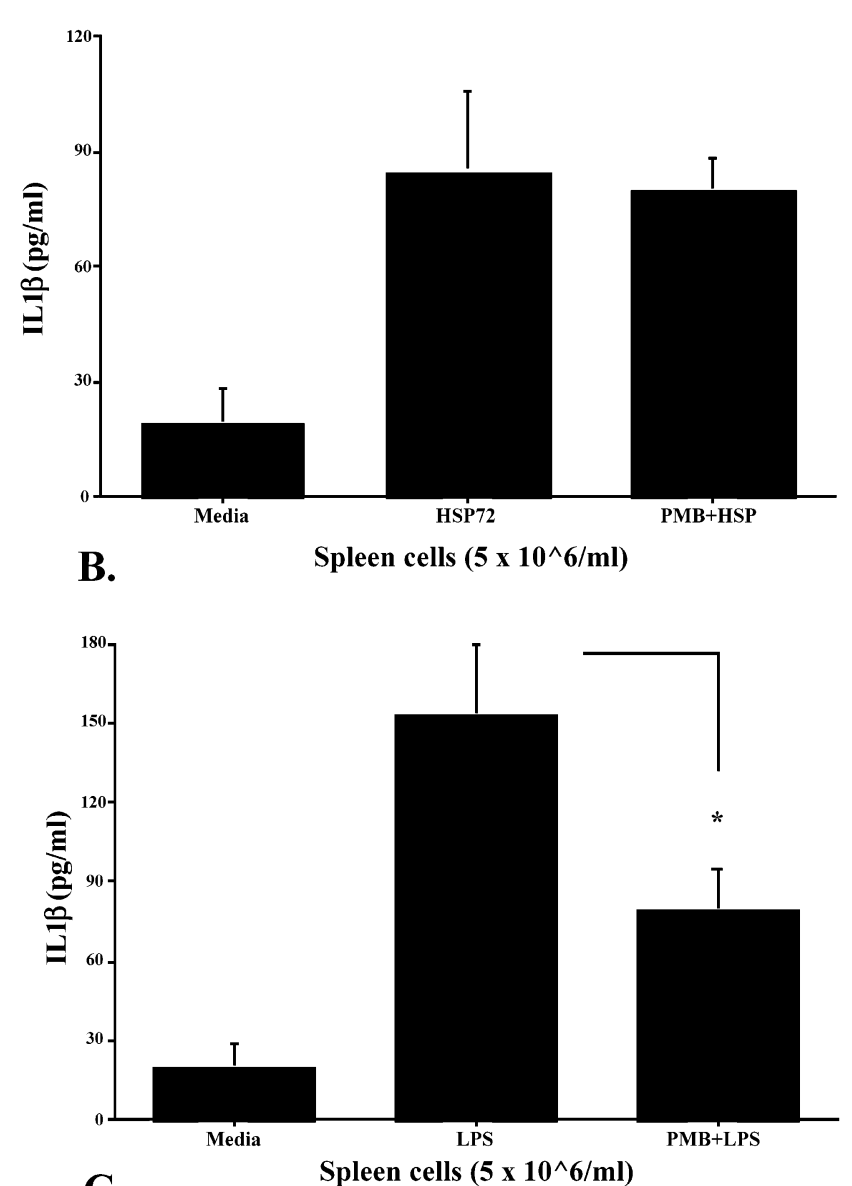

C.

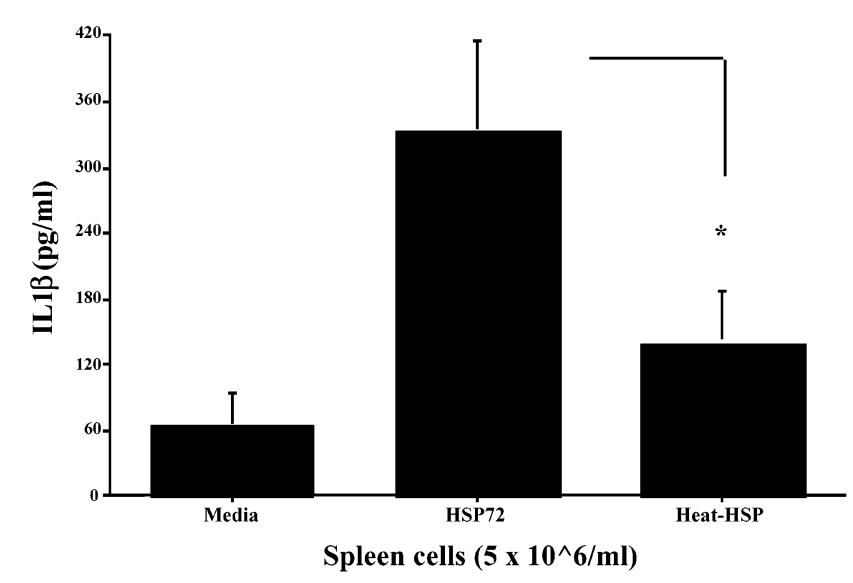

Fig 9. Adult male F344 rats $(n=12)$ were sacrificed, and splenocytes were aseptically harvested. Spleen cells $\left(5 \times 10^{6}\right.$ cells $/ \mathrm{mL}$, $300 \mu \mathrm{L} /$ well) were cultured for 24 hours with the after-stimulants: (A) culture media (media), $10 \mu \mathrm{g} / \mathrm{mL}$ of Hsp72 protein (Hsp72) or 100 $\mu \mathrm{g} / \mathrm{mL}$ of polymyxin B (PMB) $+10 \mu \mathrm{g} / \mathrm{mL}$ of Hsp72 (PMB $+\mathrm{Hsp}$ ); (B) culture media (media), $50 \mu \mathrm{g} / \mathrm{mL}$ of lipopolysaccharide (LPS) or $100 \mu \mathrm{g} / \mathrm{mL}$ of PMB $+50 \mu \mathrm{g} / \mathrm{mL}$ of LPS (PMB + LPS); or (C) culture media (media), $10 \mu \mathrm{g} / \mathrm{mL}$ of Hsp72 protein (Hsp72) or $10 \mu \mathrm{g} / \mathrm{mL}$ of Hsp72 protein that was heat treated at $100^{\circ} \mathrm{C}$ for 90 minutes (heatHsp). Interleukin 1- $\beta$ levels were measured from culture superna- was responsible for cell stimulation was addressed 3-fold. First, LPS content was measured using the Limulus amebocyte lysate assay. The assay indicated that the Hsp72 protein used in our studies contained very little endotoxin $(0.96 \mathrm{EU} / 10 \mu \mathrm{g}$ eHsp72). Endotoxin stimulation with the concentration of endotoxin contained in the eHsp72 used in these studies does not result in cytokine production in human monocytes or dendritic cells (Bethke et al 2002). Second, stimulation of cells in the presence of polymyxin $B$, a potent LPS inhibitor, significantly abrogated LPS-induced ( $P=0.01$; Fig 9A) but not Hsp72-induced $(P=0.8$; Fig 9B) cytokine production. Finally, heat-denature treatment of Hsp72 prevented the ability of Hsp72 to stimulate cytokine production ( $P=0.02 ; \mathrm{Fig} 9 \mathrm{C})$. It has been reported previously that heat-denature treatment of LPS has no effect on its ability to elicit cytokine production (Kol et al 2000). These data strongly support the conclusion that the effect was specific to eHsp72 and was not due to endotoxin contamination of the protein.

\section{Effects of stressor exposure and E coli on inflammatory site NO production}

Given that inescapable tail shock stress increases both circulating and inflammatory site eHsp72, and eHsp72 elevates $\mathrm{NO}$ and cytokine responses, the following study examined the effect of inescapable tail shock stress on the in vivo NO response to $E$ coli challenge. The results were that stressor exposure potentiated the $\mathrm{NO}$ response to $E$ coli challenge (Fig 10A). As shown in Figure 10A, E coli challenge alone compared with vehicle increased the amount of nitrite at the inflammatory site in both stress and no-stress rats. However, E coli-challenged rats exposed to stress had a significantly greater NO response than $E$ coli-challenged no-stress animals. The results are supported by a significant stress by bacteria by time interaction $(F(3,51)=7.779, P=0.0002)$. Post hoc analysis indicated significant differences in nitrite accumulation between stressed and control rats injected with bacteria after 3 and 4 hours of incubation in culture.

\section{Effect of NO inhibition on stress-induced changes in inflammation}

Figure 10B verifies that the dose of L-NIO tested was effective in reducing the NO response to bacteria. Analysis indicated a significant main effect of group (L-NIO vs vehicle; $F(1,64)=13.066, P=0.0068)$ as well as a significant group by time interaction $(F(8,64)=3.083, P=$

$\leftarrow$

tants using enzyme-linked immunosorbent assay. All figures represent mean \pm standard error of the mean. (B) LPS vs PMB + LPS, F-PLSD ${ }^{*} P<0.05$. (C) Hsp72 vs heat-Hsp, F-PLSD ${ }^{*} P<0.05$. 
A.
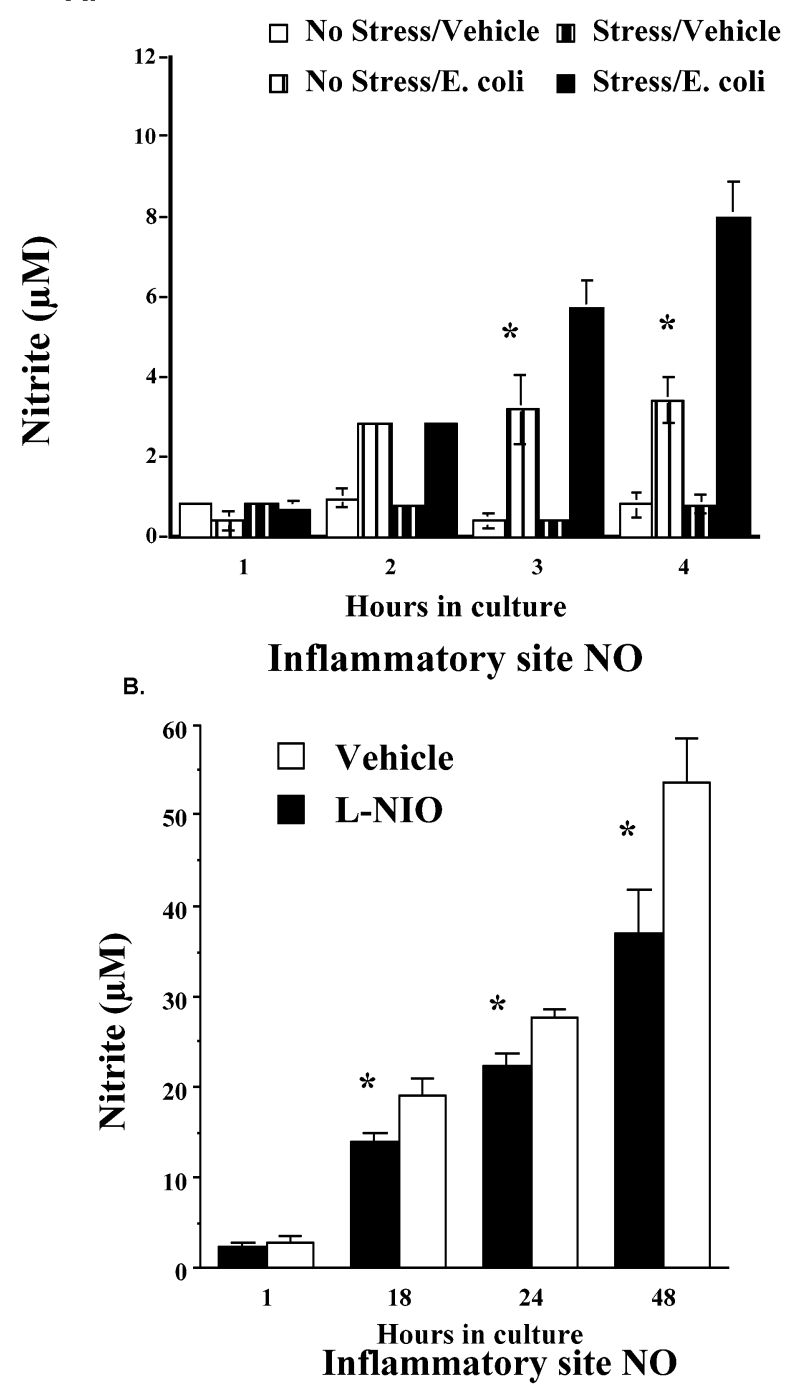

Fig 10. (A) Adult male F344 rats $(n=21)$ either were exposed to 100,5 -second, 1.6-mA inescapable tail shocks (stress) or remained in their home cages (no stress). Immediately after stressor termination, rats ( $n=4-6 /$ group) were injected with either $E$ coli $(\sim 2.5$ $\times 10^{9}$ colony-forming units [CFU]) or saline (vehicle). Two hours after stressor termination, rats were sacrificed, and inflammatory sites were aseptically dissected, cut into smaller sections, put into 2 $\mathrm{mL}$ of Hanks media, and placed in culture. Nitrite was measured from the supernatants after $1,2,3$, or 4 hours in culture. (B) Unstressed rats $(n=12)$ were injected with $E$ coli $\left(\sim 2.5 \times 10^{9} \mathrm{CFU}\right)$. After 1 hour, rats ( $n=6 /$ group) were injected again with either L$N^{5}$-(1-iminoethyl)-ornithine dihydrochloride (L-NIO) or saline (vehicle) into the inflammatory site. Rats were sacrificed 1 hour after L$\mathrm{NIO}$ injection, and their inflammatory site was aseptically dissected and placed in culture. Supernatants were collected, and nitrite was measured after 1, 18, 24, and 48 hours in culture. All figures represent mean \pm standard error of the mean. (A) Stress $(E$ coli $)$ vs no stress $(E$ coli), F-PLSD * $P<0.05$. (B) L-NIO vs vehicle, F-PLSD * $P$ $<0.05$.

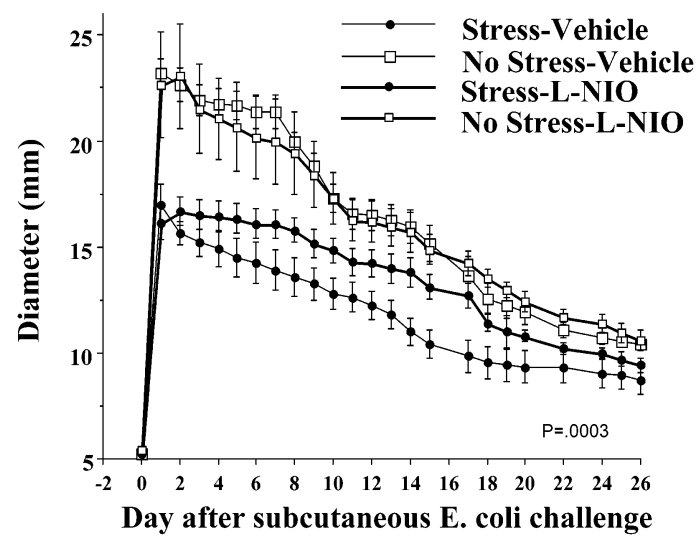

Fig 11. Adult, male F344 rats $(n=22)$ either were exposed to 100 , 5-second, 1.6-mA inescapable tail shocks (stress) or remained in their home cages (no stress). Immediately after stressor termination, all rats were injected with Escherichia coli $\left(\sim 2.5 \times 10^{9}\right.$ colony-forming units). Rats ( $n=4-6 /$ group) were then injected with equal volumes of either L- $N^{5}$-(1-iminoethyl)-ornithine dihydrochloride (L-NIO) or vehicle at $0,30,60,90,120,150$, and 180 minutes after the $E$ coli injection. Inflammation measurements were taken daily. All figures represent mean \pm standard error of the mean. Group (stress [vehicle], stress [L-NIO], no stress [vehicle], no stress [L-NIO]) by time interaction, $P=0.0003$.

0.0053). Post hoc analysis revealed that nitrite from the inflammatory site was reduced by L-NIO 18, 22, 24, and 48 hours after being placed in culture, suggesting a longlasting effect of a single injection of the inhibitor.

The previous studies demonstrated that stressor exposure elevates eHsp72, potentiates E coli-induced NO at the inflammatory site, and facilitates recovery from bacterial infection. If the potentiated-NO response is responsible for the facilitated recovery, then inhibition of $\mathrm{NO}$ at the inflammatory response should reduce the effect of stress. To test this hypothesis, rats were treated with an effective dose of L-NIO (an irreversible inhibitor of NOS) every 30 minutes for 180 minutes after $E$ coli challenge and inescapable tail shock termination. The effect of in vivo NO inhibition (L-NIO) on bacterial inflammation is presented in Figure 11. The stress-induced reduction in inflammation was significantly attenuated in rats treated with L-NIO. A one-way RMANOVA indicated that there was a significant main effect of group $(F(3,414)=10.844$, $P=0.0003)$ and a significant group by time interaction $(F(69414)=4.312, P \leq 0.0001)$. Post hoc tests revealed no effect of L-NIO on inflammation in the absence of stress. However, in the presence of stress, L-NIO reduced the impact of stress on inflammation. Post hoc analysis indicated that over time the stress + L-NIO group was reliably different from the stress + vehicle group 10, 12, 13, $14,15,17$, and 18 days after challenge.

\section{DISCUSSION}

The eHsp72 may act as a danger signal to immune cells and promote immune responses. The current results lend 


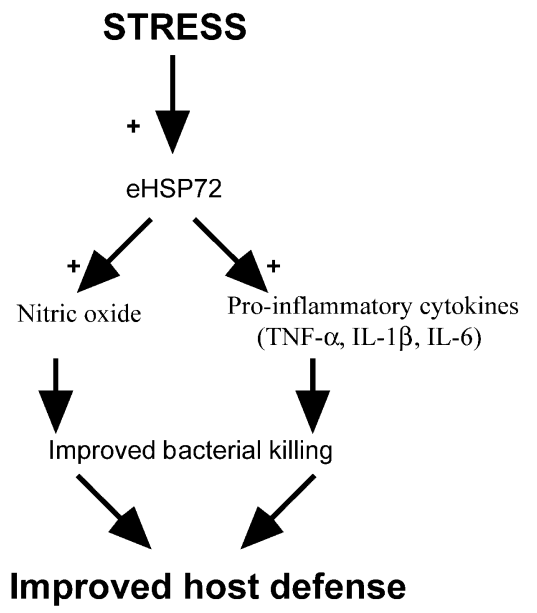

Fig 12. Schematic of how stress-induced extracellular Hsp72 (eHsp72) could be a functionally significant danger signal to the immune system. Acute stress increases eHsp72 that accumulates at the site of inflammation and facilitates bacterial-stimulated NO and cytokines released by macrophages or neutrophils (or both). Potentiated $\mathrm{NO}$ and proinflammatory cytokines facilitate bacterial killing, resulting in faster inflammation resolution and improved host defense.

support to this hypothesis. Stressor exposure does indeed increase eHsp72 (Fig 2 A,B), which may act as a danger signal to facilitate the NO response, resulting in increased bacterial killing and improved host defense (Fig 12). This is the first demonstration of the functional significance of the release of a potential danger signal to an in vivo immune response.

Inescapable tail shock stress but not restraint resulted in an increase in circulating eHsp72. The eHsp72 was increased relative to controls 25 minutes after the onset of the 100-minute stressor and remained elevated for at least 2 hours after stressor termination. If eHsp72 is facilitating the immune response to the bacterial challenge, it must be present at the inflammatory site as well. Indeed, stress-induced eHsp72 was elevated both in the circulation and at the inflammatory site. Interestingly, eHsp72 accumulated in the skin only after rats were challenged subcutaneously with bacteria (ie, not with stress alone). This could be due to extravasation of Hsp72 from the blood into the skin, triggered by other inflammatory mediators (PGE2, BK, etc) released in response to the bacteria (Ali et al 1997).

Although this is the first demonstration that exposure to a laboratory stress (inescapable tail shock) can increase the endogenous release and accumulation of eHsp72 in the blood and tissue, the current studies did not address the cellular sources or the signals responsible for eHsp72 release. Basu et al (2000) reported that eHsps are released after necrotic cell death, but it is unclear whether inescapable tail shock stress results in cell necrosis or whether other mechanisms are responsible for eHsp release. Re- cent evidence demonstrates that exposure to psychological stress is associated with high levels of eHsp60 in the circulation of humans (Lewthwaite et al 2002) and eHsp72 in the circulation of rats (Fleshner et al, in press), possibly suggesting that mechanisms other than cell necrosis lead to eHsp release. Furthermore, Febbraio et al (2002) demonstrated that exercise results in increases in eHsp72 in the circulation of humans, through the hepatosplanchnic tissue. Because the form of exercise used in this study was unlikely to cause lysis of hepatosplanchic cells, the authors suggest that hepatosplanchnic tissue may possess a specific exocytosis pathway to release Hsp72 (Febbraio et al 2002). We have reported previously that inescapable tail shock stress results in the induction of Hsp72 in the liver of rodents (Campisi et al 2003) and the release of acute-phase proteins from the liver (Deak et al 1997). Therefore, it is possible that the observed increase in circulating eHsp72 after inescapable tail shock stress is due to hepatosplanchic tissue release of eHsp72.

Inescapable tail shock stress exposure altered both development and resolution of the inflammatory response. Specifically, rats exposed earlier to stressor had a $38 \%$ reduction in inflammation after bacteria challenge, as measured by diameter on day 1 (Fig 3), and demonstrated a facilitated pattern of recovery throughout the study compared with animals not exposed to stress. These results are consistent with our previous findings (Campisi et al 2002a; Fleshner et al 2002). Significantly, previous work (Campisi et al 2002a) has demonstrated that rats exposed to inescapable tail shock stress have an equal increase in inflammation size from 0 to 5 hours after $E$ coli challenge. However, after 5 hours the development of inflammation was restricted in rats exposed to stress. The restriction in inflammation development could be indicative of faster bacterial killing at $0-5$ hours after challenge, which allowed the stressed rats to completely resolve their inflammatory response 2 weeks earlier than their nonstressed counterparts. Indeed, rats exposed to inescapable tail shock stress had significantly less viable bacteria at the inflammatory site 2, 4, and 6 hours after challenge, suggesting that they were better able to kill or clear the bacteria than control rats (Fig 1). In addition, rats exposed to inescapable tail shock stress before $E$ coli challenge lost less body weight because of the infection than did E coli-challenged controls (Campisi et al 2002). These data suggest that recovering from the infection 2 weeks earlier is indeed beneficial to the host.

If eHsp72 plays a role in the facilitation of bacteria recovery produced by stress, then injection of eHsp72 in the absence of stress should produce a similar effect. Rats injected with exogenous Hsp72 and live bacteria in vivo did demonstrate a facilitated pattern of recovery from infection, indicating that eHsp72 is sufficient to facilitate bacteria recovery. Although Hsp72 administration in the 
absence of stress did facilitate bacterial inflammation recovery, the effect was not equal to that produced by stress. This would be expected given that inescapable tail shock stress produces many changes, in addition to the increase in eHsp72, that could all contribute to facilitated bacterial inflammation recovery. For example, acute stress triggers several features of the acute-phase response, including an increase in circulating neutrophils (Fleshner et al 2002), complement function (Fleshner et al 2002), IL-6 (LeMay et al 1990; Zhou et al 1993), and acute-phase proteins (Deak et al 1997). Significantly, exposure to restraint, which does increase stress hormones (Sutton et al 1994), had no effect on eHsp72 or bacterial recovery. These data also support the hypothesis that eHsp72 contributes to stress-induced facilitation of recovery after bacterial challenge.

Hsp72 in vitro induces nitric oxide dose dependently, TNF- $\alpha$, IL-1 $\beta$, and IL- 6 directly. As has been previously reported in human and murine cells, F344 rat peritoneal cells and splenocytes responded robustly to eHsp72 alone. In fact, 5 times less eHsp72 than LPS was needed to produce a nearly equivalent response. This is the first time the effect of Hsp72 has been tested in F344 rat cells, extending the generality of this effect across species. Both populations of cells responded to the combination of Hsp72 + LPS with greater NO and cytokines than was observed after stimulation with Hsp72 or LPS alone. These results are consistent with our hypothesis that eHsp72 facilitates the innate immune response to bacterial challenge. Significantly, the effect of Hsp72 on $\mathrm{NO}$ and cytokine production was not due to endotoxin contamination. This conclusion is supported by the fact that (1) eHsp72 had $0.96 \mathrm{EU} / 10 \mu \mathrm{g}$ of eHsp72, (2) endotoxin stimulation with the concentration of endotoxin contained in the eHsp72 used in these studies has been found to be insufficient to stimulate cytokine production (Bethke et al 2002), (3) polymyxin B (LPS inhibitor) did not reduce eHsp72-induced release but did reduce LPS-induced release of IL1- $\beta$, and (4) heat denaturing prevented eHsp72induced release of IL1- $\beta$. Furthermore, the quantities of eHsp shown here to stimulate cells in vitro and facilitate recovery in vivo, although greater than the levels measured presently in the circulation and tissue, are well within the range expected to be released locally as a result of cell lysis in vivo (Basu et al 2000).

Hsp72 in vitro and stressor exposure in vivo, both elevate NO. Given that inescapable tail shock stress increases eHsp72 at the inflammatory site, and elevated NO facilitates bacterial killing, it is possible that eHsp72 released by stress facilitates bacterial inflammatory recovery by enhancing specifically the NO response. In fact, attenuating the production of NO did reduce the stressinduced facilitation of bacterial inflammation recovery. The reduction was demonstrable several days after ex- posure to stress and E coli. NO plays many diverse roles in bacterial inflammation, ranging from changes in cellular migration to vasodilation and bactericidal function (Fang 1997). Given that L-NIO had no effect on the kinetics of bacterial inflammation in the absence of stress, and that the reduction of the effect of stress occurred after several days, we propose that L-NIO produced its effect by preventing the stress-induced (through eHsp72) potentiation of NO. L-NIO is probably still exerting its effect days after its administration, given the long-lasting effect of a single injection of L-NIO. In the in vivo study, 7 injections of L-NIO were given over several hours to ensure that its effectiveness would persist even longer.

It is interesting to note that the degree of facilitation in bacterial recovery produced by the administration of eHsp72 in the absence of stress is nearly equal to the amount of inhibition of the stress-induced facilitation in bacterial inflammation produced by L-NIO. Specifically, Hsp72 administration resulted in a 10\% reduction (33.95 vs $37.83 \mathrm{~mm}$; day 1) in inflammation, and L-NIO resulted in a $12 \%$ reduction (stress $=26 \%$ reduction, $\mathrm{L}-\mathrm{NIO}+$ stress $=14 \%$ reduction; day 10 ) of the effect of stress. These results support the hypothesis that exposure to inescapable tail shock stress increases eHsp72, which leads to a facilitation in $\mathrm{NO}$ and a potentiation in recovery from bacterial inflammation.

It is possible that exposure to an acute, relatively intense stressor such as inescapable tail shock triggers a global stress response whose adaptive function is, in part, to trigger a global danger signal to the body. In fact, it has been suggested recently that exposure to acute stress may prime or facilitate features of innate immunity that enable the organism to better survive infection after injury (Deak et al 1997, 1999; Campisi et al 2002a; Fleshner et al 2002). The current series of studies suggest that 1 important mechanism for stress-induced priming of innate immunity may be the release of eHsp72, which in turn acts as a danger signal for the immune system.

One limitation of this series of studies was the inability to block the Hsp72 response in vivo. For example, it would be ideal to block the receptor to which the Hsp72 protein binds. Unfortunately, the Hsp72 receptor has not yet been clearly identified in the rat, and there is no antagonist that has been identified to date. There is evidence suggesting the existence of a cell surface receptor for Hsp70 on macrophages (Sondermann et al 2000), which was later identified as the $\alpha_{2}$-macroglobulin receptor (Basu et al 2001). In addition, there is recent evidence that TLR2, TLR4, and the Toll/IL-1 receptor signal pathway may serve as functional cell surface receptors for eHsp72 (Asea et al 2002; Vabulas et al 2002). Future work will attempt to specifically block this receptor to examine its role in relaying the danger signal.

The earliest Hsp research documented the ability of 
intracellular Hsp72 to function as a protein chaperone and, subsequently, to serve protective functions within cells (Kiang and Tsokos 1998). Recent data support the hypothesis that eHsp72 acts as a danger signal to the immune system, and a functional role for this action has also emerged. Specifically, results from this series of studies indicate that eHsp72 is sufficient to induce physiologically relevant facilitated recovery after bacteria challenge and suggest that activation of the innate immune system in response to stress may represent an anticipatory defensive immune response. Previous work has demonstrated that Hsps can be powerful adjuvants for eliciting immune responses and may stimulate antitumor immunity (Suto and Srivastava 1995; Tamura et al 1997; Srivastava et al 1998; Todryk et al 1999). The current studies suggest that acute stressor exposure results in the release of endogenous Hsp and that this may be an adaptive response for many aspects of immunity.

\section{ACKNOWLEDGMENTS}

We thank Julianna West for excellent technical assistance. This work was supported by grants (to M.F.) from the National Institutes of Health, AI-48555 and MH-060301.

\section{REFERENCES}

Ali H, Haribabu B, Richardson RM, Snyderman R. 1997. Mechanisms of inflammation and leukocyte activation. Med Clin North Am 81: 1-28.

Asea A, Kraeft SK, Kurt-Jones EA, Stevenson MA, Chen LB, Finberg RW, Koo GC, Calderwood SK. 2000. HSP70 stimulates cytokine production through a CD14-dependant pathway, demonstrating its dual role as a chaperone and cytokine. Nat Med 6: 435-442.

Asea A, Rehli M, Kabingu E, Boch JA, Bare O, Auron PE, Stevenson MA, Calderwood SK. 2002. Novel signal transduction pathway utilized by extracellular HSP70: role of toll-like receptor (TLR) 2 and TLR4. J Biol Chem 277: 15028-15034.

Basu S, Binder RJ, Ramalingam T, Srivastava PK. 2001. CD91 is a common receptor for heat shock proteins gp96, hsp90, hsp70, and calreticulin. Immunity 14: 303-313.

Basu S, Binder RJ, Suto R, Anderson KM, Srivastava PK. 2000. Necrotic but not apoptotic cell death releases heat shock proteins, which deliver a partial maturation signal to dendritic cells and activate the NF-kappa B pathway. Int Immunol 12: 1539-1546.

Bethke K, Staib F, Distler M, Schmitt U, Jonuleit H, Enk AH, Galle PR, Heike M. 2002. Different efficiency of heat shock proteins (HSP) to activate human monocytes and dendritic cells: superiority of HSP60. J Immunol 169: 6141-6148.

Breloer M, Dorner B, More SH, Roderian T, Fleischer B, von Bonin A. 2001. Heat shock proteins as "danger signals": eukaryotic Hsp60 enhances and accelerates antigen-specific IFN-gamma production in T cells. Eur J Immunol 31: 2051-2059.

Breloer M, Fleischer B, von Bonin A. 1999. In vivo and in vitro activation of $\mathrm{T}$ cells after administration of Ag-negative heat shock proteins. J Immunol 162: 3141-3147.

Cahill CM, Lin HS, Price BD, Bruce JL, Calderwood SK. 1997. Potential role of heat shock transcription factor in the expression of inflammatory cytokines. Adv Exp Med Biol 400B: 625-630.
Cahill CM, Waterman WR, Xie Y, Auron PE, Calderwood SK. 1996. Transcriptional repression of the prointerleukin 1beta gene by heat shock factor 1. J Biol Chem 271: 24874-24879.

Campisi J, Leem TH, Fleshner M. 2002. Acute stress decreases inflammation at the site of infection. A role for nitric oxide. Physiol Behav 77: 291-299.

Campisi J, Leem TH, Greenwood BN, Hansen MK, Moraska A, Higgins K, Smith TP, Fleshner M. 2003. Habitual physical activity facilitates stress-induced HSP72 induction in brain, peripheral and immune tissues. Am J Physiol, 284: R520-R530.

Chen W, Syldath U, Bellmann K, Burkart V, Kolb H. 1999. Human $60-\mathrm{kDa}$ heat-shock protein: a danger signal to the innate immune system. J Immunol 162: 3212-3219.

Colaco CA. 1998. Towards a unified theory of immunity: dendritic cells, stress proteins and antigen capture. Cell Mol Biol (Noisyle-grand) 44: 883-890.

Deak T, Meriwether JL, Fleshner M, et al., 1997. Evidence that brief stress may induce the acute phase response in rats. Am J Physiol 273: R1998-R2004.

Deak T, Nguyen KT, Fleshner M, Watkins LR, Maier SF. 1999. Acute stress may facilitate recovery from a subcutaneous bacterial challenge. Neuroimmunomodulation 6: 344-354.

Duff GW, Atkins E. 1982. The inhibitory effect of polymyxin B on endotoxin-induced endogenous pyrogen production. J Immunol Methods 52: 333-340.

Fang FC. 1997. Perspectives series: host/pathogen interactions. Mechanisms of nitric oxide-related antimicrobial activity. J Clin Invest 99: 2818-2825.

Febbraio MA, Ott P, Nielsen HB, Steensberg A, Keller C, Krustrup $\mathrm{P}$, Secher NH, Pedersen BK. 2002. Exercise induces hepatosplanchnic release of heat shock protein 72 in humans. J Physiol 544: 957-962.

Fleshner M. 2000. Exercise and neuroendocrine regulation of antibody production: protective effect of physical activity on stressinduced suppression of the specific antibody response. Int $J$ Sports Med 21: S14-S19.

Fleshner M, Campisi J, Deak T, Greenwood BN, Kintzel JA, Leem TH, Smith TP, Sorensen B. 2002. Acute stressor exposure facilitates innate immunity more in physically active than in sedentary rats. Am J Physiol Regul Integr Comp Physiol 282: R1680R1686.

Fleshner M, Nguyen KT, Cotter CS, Watkins LR, Maier SF. 1998. Acute stressor exposure both suppresses acquired immunity and potentiates innate immunity. Am J Physiol 275: R870-R878.

Fleshner M, Watkins LR, Lockwood LL, Grahn RE, Gerhardt G, Meaney MJ, Laudenslager ML, Maier SF. 1993. Blockade of the hypothalamic-pituitary-adrenal response to stress by intraventricular injection of dexamethasone: a method for studying the stress-induced peripheral effects of glucocorticoids. Psychoneuroendocrinology 18: 251-263.

Golenbock DT, Hampton RY, Qureshi N, Takayama K, Raetz CR. 1991. Lipid A-like molecules that antagonize the effects of endotoxins on human monocytes. J Biol Chem 266: 19490-19498.

Habich C, Baumgart K, Kolb H, Burkart V. 2002. The receptor for heat shock protein 60 on macrophages is saturable, specific, and distinct from receptors for other heat shock proteins. J Immunol 168: 569-576.

Hartl FU. 1996. Molecular chaperones in cellular protein folding. Nature 381: 571-579.

Housby JN, Cahill CM, Chu B, Prevelige R, Bickford K, Stevenson MA, Calderwood SK. 1999. Non-steroidal anti-inflammatory drugs inhibit the expression of cytokines and induce HSP70 in human monocytes. Cytokine 11: 347-358.

Johnson JD, O'Connor KA, Deak T, Stark M, Watkins LR, Maier SF. 
2002. Prior stressor exposure sensitizes LPS-induced cytokine production. Brain Behav Immun 16: 461-476.

Kiang JG, Tsokos GC. 1998. Heat shock protein 70 kDa: molecular biology, biochemistry, and physiology. Pharmacol Ther 80: 183201.

Kol A, Lichtman AH, Finberg RW, Libby P, Kurt-Jones EA. 2000. Cutting edge: heat shock protein (HSP) 60 activates the innate immune response: CD14 is an essential receptor for HSP60 activation of mononuclear cells. J Immunol 164: 13-17.

LeMay LG, Vander AJ, Kluger MJ. 1990. The effects of psychological stress on plasma interleukin-6 activity in rats. Physiol Behav 47: 957-961.

Lewthwaite J, Owen N, Coates A, Henderson B, Steptoe A. 2002. Circulating human heat shock protein 60 in the plasma of British civil servants: relationship to physiological and psychosocial stress. Circulation 106: 196-201.

Lindquist S, Craig EA. 1988. The heat-shock proteins. Annu Rev Genet 22: 631-677.

Matzinger P. 1994. Tolerance, danger, and the extended family. Annu Rev Immunol 12: 991-1045.

Matzinger P. 1998. An innate sense of danger. Semin Immunol 10: 399-415.

McCall TB, Feelisch M, Palmer RM, Moncada S. 1991. Identification of N-iminoethyl-L-ornithine as an irreversible inhibitor of nitric oxide synthase in phagocytic cells. Br J Pharmacol 102: 234-238.

Milne KJ, Noble EG. 2002. Exercise-induced elevation of HSP70 is intensity dependent. J Appl Physiol 93: 561-568.

Moseley PL. 1998. Heat shock proteins and the inflammatory response. Ann N Y Acad Sci 856: 206-213.

Multhoff G, Mizzen L, Winchester CC, et al. 1999. Heat shock protein 70 (Hsp70) stimulates proliferation and cytolytic activity of natural killer cells. Exp Hematol 27: 1627-1636.

Ohashi K, Burkart V, Flohe S, Kolb H. 2000. Cutting edge: heat shock protein 60 is a putative endogenous ligand of the toll-like receptor-4 complex. J Immunol 164: 558-561.

Panjwani NN, Popova L, Srivastava PK. 2002. Heat shock proteins gp96 and hsp70 activate the release of nitric oxide by APCs. J Immunol 168: 2997-3003.

Rodenas J, Mitjavila MT, Carbonell T. 1998. Nitric oxide inhibits su- peroxide production by inflammatory polymorphonuclear leukocytes. Am J Physiol 274: C827-C830.

Rojas IG, Padgett DA, Sheridan JF, Marucha PT. 2002. Stress-induced susceptibility to bacterial infection during cutaneous wound healing. Brain Behav Immun 16: 74-84.

Sondermann H, Becker T, Mayhew M, Wieland F, Hartl FU. 2000. Characterization of a receptor for heat shock protein 70 on macrophages and monocytes. Biol Chem 381: 1165-1174.

Srivastava PK, Menoret A, Basu S, Binder RJ, McQuade KL. 1998. Heat shock proteins come of age: primitive functions acquire new roles in an adaptive world. Immunity 8: 657-665.

Suto R, Srivastava PK. 1995. A mechanism for the specific immunogenicity of heat shock protein-chaperoned peptides. Science 269: 1585-1588.

Sutton LC, Fleshner M, Mazzeo R, Maier SF, Watkins LR. 1994. A permissive role of corticosterone in an opioid form of stressinduced analgesia: blockade of opiate analgesia is not due to stress-induced hormone release. Brain Res 663: 19-29.

Tamura Y, Peng P, Liu K, Daou M, Srivastava PK. 1997. Immunotherapy of tumors with autologous tumor-derived heat shock protein preparations. Science 278: 117-120.

Todryk S, Melcher AA, Hardwick N, Linardakis E, Bateman A, Colombo MP, Stoppacciaro A, Vile RG. 1999. Heat shock protein 70 induced during tumor cell killing induces Th1 cytokines and targets immature dendritic cell precursors to enhance antigen uptake. I Immunol 163: 1398-1408.

Todryk S, Melcher AA, Dalgleis AG, Vile RG. 2000. Heat shock proteins refine the danger theory. Immunology 99: 334-337.

Vabulas RM, Ahmad-Nejad P, Ghose S, Kirschning CJ, Issels RD, Wagner H. 2002. HSP70 as endogenous stimulus of the Toll/ interleukin-1 receptor signal pathway. J Biol Chem 277: 1510715112.

Yoo CG, Lee S, Lee CT, Kim YW, Han SK, Shim YS. 2000. Antiinflammatory effect of heat shock protein induction is related to stabilization of I kappa B alpha through preventing I kappa B kinase activation in respiratory epithelial cells. J Immunol 164: 5416-5423.

Zhou D, Kusnecov AW, Shurin MR, DePaoli M, Rabin BS. 1993. Exposure to physical and psychological stressors elevates plasma interleukin 6: relationship to the activation of hypothalamic-pituitary-adrenal axis. Endocrinology 133: 2523-2530. 